\title{
Sharing Economy: A Bibliometric Analysis, Research Trends and Research Agenda
}

\author{
Carlai de Oliveira Netto ${ }^{1}$, Jorge Estuardo Tello-Gamarra ${ }^{2 \star}$
}

\begin{abstract}
Sharing economy is an area that has been attracting increased interest from entrepreneurs and academics thanks to its notable growth. This study intends to present a quantitative panorama of studies related to the sharing economy, and to identify research trends and propose an agenda for future studies. In order to accomplish this, we applied the bibliometric method (bibliographic coupling) to data extracted from the Scopus Database. This is a relatively new field of study, originating in the socio-marketing interests related to the act of sharing and evolving from there until the most recent studies, which are based on sharing platforms and new technologies. Based on the identified research trends and their overlapping of one another, we propose some questions that may be the target of future studies and would contribute to this field of research.
\end{abstract}

Keywords: Bibliographic coupling; Bibliometrics; Collaborative consumption; Research Agenda; Scopus; Sharing economy.

Submitted: April 23 $3^{\text {rd }}, 2020$ / Approved: August 19 $9^{\text {th }}, 2020$

\section{Introduction}

The act of sharing is not new to human behavior, having been the basic form of economic distribution in hominid society for thousands of years (Price, 1975). Currently, this behavior is expressed mainly through the sharing of properties that until recently were considered individual such as vehicles and real estate (Muñoz and Cohen, 2017); on the internet, through the significant sharing of information and other media (Belk, 2010); as well as through the joint usage of services or intangible goods, which occurs in coworking spaces (Brown, 2017). This is attributed to the appearance and growth of the so-called sharing economy. If on one side sharing is not considered a new practice because it has always happened among those belonging to the same group or social circle, in the sharing economy, the act of sharing with strangers is the factor that makes all the difference (Frenken and Schor, 2017).

The sharing economy's position as a phenomenon to study has been steadily attracting more attention, with companies in this category reaching expressive growth indexes (Schor, 2014). Two of the greatest examples of success in their fields, Uber and Airbnb (Martin, 2016), reached a valuation estimated at 120 and 38 billion dollars respectively, with a projection for public listing in the stock market in 2019 (Bloomberg, 2018; Forbes, 2018). Furthermore, it is projected that by 2021, the number of adults in the United States using services contained within the sphere of sharing economy will be over 85 million people (Emarketer, 2017). This success has been motivating an increasingly large number of companies that are popping up under this business model (Ert et al., 2016), also encouraged by the acceptance that sharing is gaining in the consumer market (Cohen and Kietzmann, 2014). With this in mind, it is possible to state that the sharing economy can no longer be seen as simply another niche trend, but is actually a competitive business model when compared with traditional service providers (Möhlmann, 2015).
The sharing economy has reached great relevance in practical terms and, in the academic world, researchers have also attributed great importance to this field of research (Martin, 2016) through a growing number of studies related to this subject (Ertz and Leblanc-Proulx, 2018). Although the number of studies about this research field has grown exponentially, bibliometric studies that used bibliographic coupling as a data analysis technique were not identified in searches within the main scientific knowledge databases. For fields of study that are still in their beginning stages, it is more interesting to use the bibliographic coupling method since the subject's epistemological roots are still being developed (Zupic and Cater, 2014). Thus, by adopting a technique that is different from the one generally used in bibliometric studies proposing to analyze the field of the sharing economy (co-citation analysis, as used by Ertz and Leblanc-Proulx, 2018 and Sainaghi et al., 2020), the objective of this article is to present a quantitative panorama of studies related to the sharing economy, as well as a map of the main research lines that are being adopted and to propose an agenda for future research. By using this new approach, we intend to contribute to the studies that are being conducted on the sharing economy. Through this contribution we expect that, even if done indirectly by proposing new studies to be developed, it will be possible to contribute practically to the field's development in different sectors.

It is also important to point out that, as identified by Vogel and Güttel (2012), said bibliometric tools (co-citation analysis and bibliographic coupling) must not be seen as competitors, but as being complementary to one another. Thus, we expect to enrich the knowledge about studies that have already been conducted and amplify the perception about them, as well as to discuss the lines of current research and directions for future studies by analyzing the past, present and future of research in the area.

Following this introduction, the next section is dedicated to a literature review about the sharing economy, its limits, origins and implications. The following section contains the methods for data

(1) Institute of Economic, Administrative and Accounting Sciences, Federal University of Rio Grande (FURG), Brazil

(2) School of Chemistry and Food, Federal University of Rio Grande (FURG), Santo Antônio da Patrulha, RS, Brazil.

${ }^{*}$ Corresponding author: jorgetellogamarra@gmail.com 
collection, purification and analysis. Finally, the bibliometric results are presented and discussed in various analysis units, followed by the discussion of research trends and the agenda for future studies. In conclusion, the most relevant results are revisited, and the study's limitations and theoretical and practical contributions come to light.

\section{The sharing economy in the literature}

If the act of sharing has always been present in societal behavior, albeit to a lesser degree and among acquaintances (Belk, 2010; Frenken and Schor, 2017), its association with the term sharing economy (and all other synonyms) is considered recent, having been "coined" only in the last few years (Schor, 2014). Despite the various studies that have already been conducted on the theme, there is still a lack of uniformity among the researchers regarding the nomenclature that must be used (Ranjbari et al., 2019), which makes it possible to observe the use of the terms "sharing economy", "collaborative economy", "peerto-peer", "access-based consumption", "gig economy”, "grassroots economy", "on-demand economy", "platform economy" or "collaborative consumption" in reference to the same concept. Aside from the lack of consensus about which term should be used, the literature still demonstrates a lack of the understanding that would be needed to reach a clear definition about what the sharing economy is (Hamari et al., 2015; Schor, 2014). Botsman and Rogers (2010a) define the sharing economy as traditional sharing, exchange, loan, negotiation, rental, donation or the exchange of goods and services among people. Belk (2014a) considers only activities that involve compensation, using the term "pseudo-sharing" to define those activities in which the transaction is conducted in the form of a short-term rental; Frenken and Schor (2017) exclude the sale of goods as a part of the sharing economy, since the access/transaction referring to the good is not temporary, but permanent. Due to this lack of uniformity in the concepts, the debate surrounding the regulatory issues of collaborative consumption is large, and involves work (Hagiu and Wright, 2018) and fiscal issues (Laurell and Sandström, 2017). These three different definitions serve only to illustrate the variety of existing definitions, which apparently vary from study to study according to which theoretical lens is applied.

If on one side the definitions and concepts diverge, the same cannot be extended to the origins and to the factors that are considered the motivators of this new phenomenon. Practically speaking, the sharing economy first appeared around 1995, with the emergence of two goods recirculation marketplaces that are still active today, eBay and Craigslist (Schor, 2014), even though they only began to attract major attention and establish their own identities with the growth of Airbnb around 2008 (Botsman and Rogers, 2010a; Martin, 2016). Thus, as it is currently defined, the sharing economy is considered a recent phenomenon, a viable alternative to fulfill the many needs of consumers that up to then were mostly satisfied by traditional companies (Zervas et al., 2017). Although many of the platforms that use this modus operandi were created in the United States, sharing became a global phenomenon thanks to the expansion of these platforms to other countries and to the fact that the idea of sharing has spread around the world, with some cities even becoming sharing centers
(Schor, 2014). Many studies pinpoint the 2008 world crisis as one of the factors behind the promotion of this type of consumption (Belk, 2014a; Botsman and Rogers, 2010a; Cohen and Kietzmann, 2014) and for the paradigmatic shifts in societal consumption (Zervas et al., 2017). Due to this event, the rental of goods became more advantageous, economically speaking, which created the conditions for the proliferation of similar initiatives (Schor, 2014). Aside from the crisis, another impacting factor was society's growing environmental conscience (Belk, 2014a; Botsman and Rogers, 2010a; Cohen and Kietzmann, 2014; Hamari et al., 2015). Finally, the development of information and communication technologies, such as the internet (Botsman and Rogers, 2010a; Cohen and Kietzmann, 2014), are shown to be equally important, being responsible for simplifying the sharing of both goods and services, physical or not (Hamari et al., 2015), by reducing the high transaction costs that existed until that point and using the appropriate tools to reduce the risks of transactions that involve third parties outside of one's habitual circle (Schor, 2014).

For the purposes of this study, the most common names in literature will be taken into consideration based on what was identified by Ertz and Leblanc-Proulx (2018). Regarding the concept of sharing economy, only the one proposed by Botsman and Rogers (2010a) will be used, as it is considered the broadest definition. This will avoid the possibility of eliminating studies during the data purification stage simply because they analyzed organizations or practices that, for some reason, would have been excluded from the sharing economy category according to any of the other authors.

\section{Methods}

The bibliometric analysis provides insight and contributes to the information about the literature pertaining to a certain field (Ellegaard, 2018), being used in many areas of research for various ends (Mongeon and Paul-Hus, 2015). The importance of this type of study rests upon the fact that possessing knowledge about the people and institutions that are conducting research, as well as the locations in which this research is being published, is relevant to identify those who will be capable of providing the best conceptual or methodological contributions (Podsakoff et al., 2008). In the present study, two bibliometric techniques are used to conduct the analysis. Citation analysis, which is more common in this type of study, is carried out through the exposure of lists and rankings (Zupic and Cater, 2014) and the formation of networks and clusters through bibliographic coupling. and bibliographic coupling through the formation of networks and clusters. This technique is based on the references that two documents have in common and measures the similarity between them. The greater the number of publications in common cited by the studies, the closer their relation (Kessler, 1963).

In order to make this analysis viable, the search was conducted on one of the largest scientific knowledge databases. Elsevier's Scopus is the largest database of abstracts and citations in peer-reviewed literature, whether from scientific journals, books or conference papers (Elsevier, 2019). Although we considered using other databases such as the Web of Science, which is also recognized by the scientific community, 
studies point to the fact that both have similar coverage (Harzing and Alakangas, 2016). Thus, the decision was made to use only Scopus, as it is considered one of the main data sources (Mongeon and PaulHus, 2015) and the use of a second database with similar coverage would not bring significantly different results.

Data collection happened in January of 2019 and the search was conducted with the terms "sharing economy", "collaborative economy" and "collaborative consumption" in the article title, abstract and keywords fields. As limiters, we only set the final year of publication as 2018, not setting any start date or filters to define knowledge areas. These search terms were obtained considering the studies conducted by Cheng (2016), Ertz and Leblanc-Proulx (2018) and Sainaghi et al. (2020). Although they consider terms related to tourism and hospitality (which direct their searches), here we chose not to use them because our approach is broad and not directed at any specific sector.

The search was carried out without being restricted to scientific articles in order to conduct a more reliable analysis of the number of studies and, as suggested by Cheng (2016), to consider grey literature. The search results were exported to Endnote Software X9, which was used for the initial data treatment and purification. At first, the studies were verified in order to see which ones actually had the sharing economy as their subject. This was done by the authors, who individually read through the keywords and abstracts of all studies, excluding those which had nothing to do with the field of research. In case of a divergence between the authors' analyses, the studies in question were discussed individually in order to reach a consensus. With this, there was a reduction from the 1405 studies that were found in the initial search to a total of 1018 studies, which were used for this research. Said reduction may be explained by the fact that many studies cite the context of sharing economy only in order to explain the current economic scenario or even by the use of terms such as "uberization" to explain a phenomenon, but without any real connection to the field of study.

After this first stage, the treated data was exported in Excel format, organized by the citation analysis results, as demonstrated in the number of publications, as well as in the number of citations, aside from the use of other indicators so that the researchers may decide which one to adopt when considering the study's influence. Some studies use the number of publications as the most relevant factor in measuring the influence of a researcher or an institution (Podsakoff et al., 2008), whereas others defend using the number of citations in order to measure said influence (Bonilla et al., 2015). Other forms of measurement, such as the h-index (Hirsch, 2005), obtained through the $\mathrm{X}$ number of studies from a certain analysis unit that received at least the same $\mathrm{X}$ number of citations; and also the P/Pop indexes (total of publications divided by the country's population) and C/P (total of citations divided by the total of publications) (Merigó et al., 2015), were also used so that the study can satisfy the needs of the greatest possible number of researchers. Due to the need to establish rank to order the results, we chose to use the number of publications, since some studies stand out thanks to the large number of citations and, as the research field is still growing, we understood that if the results were ranked by any other indicator, it might be harder to visualize the data.

Finally, for the mapping and cluster analysis, we used the bibliographic coupling technique. All publications were imported to the VosViewer software (Van Eck and Waltman, 2010), and a mapping of the existing relations was generated through the visualization of similarities method (Van Eck and Waltman, 2007). We chose VosViewer instead of any other software because, unlike other programs that are normally used for bibliometric mapping (such as SPSS and Pajek), VosViewer focuses on the graphic representation of bibliometric maps, presenting these in a manner that is easy to interpret (Van Eck and Waltman, 2010). This software's use in studies related to the sharing economy field may be observed in the systematic review recently conducted by Sainaghi et al. (2020), as well as in the methodology proposed by Ertz and Leblanc-Proulx (2019), which is based on the collaboration economy.

To conduct the mapping, the chosen analysis unit was "documents" in order to verify which studies are in the front lines of the research field (Zupic and Cater, 2014) and may indicate the direction taken by the area, something which is deemed to be necessary by Martin (2016). In order to reduce the number of documents and streamline their visualization in the mapping, the process was limited to articles with at least 15 citations that showed a connection strength of at least $20 \%$ to the article with the greatest value. This was used as a manner of excluding articles that showed low relevance to the field or that were isolated from the others and left a total of 73 articles to be mapped. It is important to note that previous studies (Sánchez-Riofrío et al., 2014; Vogel and Güttel, 2012) had already signaled an apparent need for good judgment from the researcher regarding the decision of which criteria should be chosen and the number of documents to be mapped, since there is no clear orientation for these matters. Furthermore, the methodology proposed by Ertz and Leblanc-Prouxl (2019) indicates that the number of citations should vary between 20 and 30 so that there isn't a large number of documents. Here, however, a larger scope was desired so we chose to set the cut-off point at 15 citations. Once the articles were mapped, it was possible to define the research problems that were being addressed in this study through individual reading.

\section{Results and Discussion}

\subsection{Bibliometrics analysis}

The data related to the bibliometrics analysis will be presented in this section. The evolution of research about the sharing economy over the years and the main keywords used by these studies, as well as a panorama about the main producers of knowledge and studies produced in this field will be approached sequentially. These results aim to demonstrate the spectrum of knowledge production in this field of research up to now and will be important in order to discuss and analyze the next steps in this article; that is, research trends and research agenda. 


\subsubsection{Evolution of the research throughout the years}

The sharing economy research field has been attracting increased attention (Martin, 2016). This can be corroborated by the evolution of the number of studies published on the subject in the last few years, which can be visualized in Figure 1. Aside from the number of publications per year, it is also interesting to note the types of publications which exist at this point. From the universe of studies, articles (61\%) and conference papers (24\%), we obtain $86 \%$ of the publications, complemented by book chapters (6\%), reviews (4\%) and editorials, notes and books ( $1 \%$ each).

Figure 1. Total of documents published per year about the sharing economy

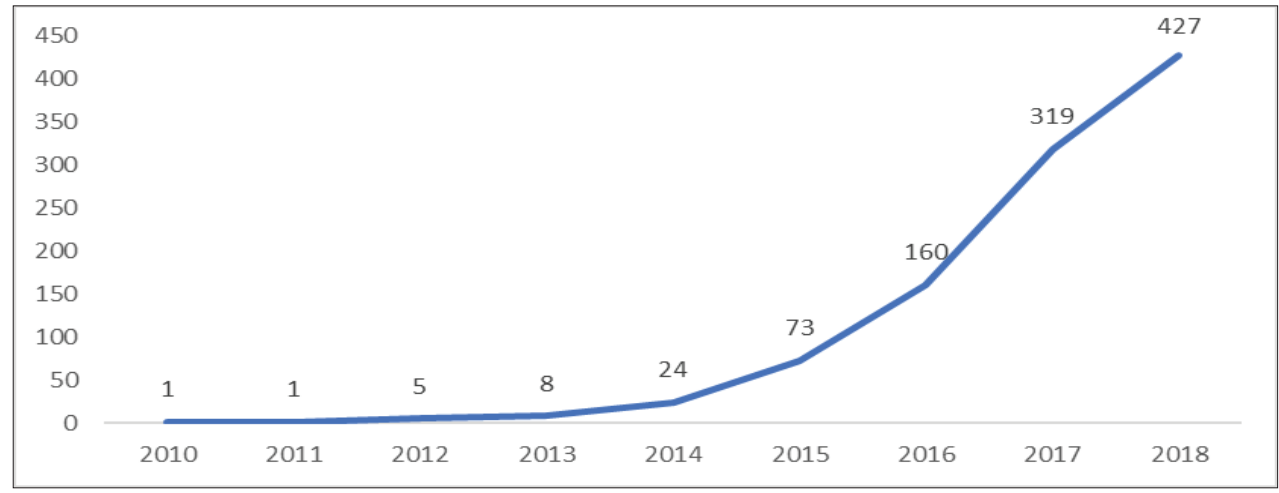

Despite the appearance of some platforms in the 1990s, the subject only became the target of academic studies beginning in 2010. At this point, it is interesting to note the first document published, by Botsman and Rogers (2010b). In this document, which is a note in the Harvard Business Review, the authors sorted the sharing platforms into three different types of systems: product service systems, redistribution markets and collaborative lifestyles. These three systems may also be found in a book written by the same authors, which is seen as one of the milestones of the sharing economy literature (Bostman and Rogers, 2010a).

\subsubsection{Most used keywords}

Although the number of studies analyzed here is $40 \%$ larger than the number analyzed by Ertz and Leblanc-Proulx (2018), the most used keywords in the database follow the findings of the previous study. Among the 1018 documents, terms that are used as names for the phenomenon, such as sharing economy and collaborative consumption; exponent companies, such as Airbnb; and the affected areas, such as economy and sustainability keep on appearing as the main keywords, as shown in Table 1.

Table 1. Most used keywords in documents related to the sharing economy

\begin{tabular}{l|c|l|c}
\hline Keyword & Occurrences & Keyword & Occurrences \\
\hline Sharing Economy & 535 & Distributed Computer Systems & 48 \\
\hline Collaborative Consumption & 149 & Sharing & 42 \\
\hline Airbnb & 123 & Internet & 38 \\
\hline Economics & 94 & Trust & 37 \\
\hline Collaborative Economy & 61 & Peer to Peer & 35 \\
\hline Sustainability & 60 & Innovation & 34 \\
\hline Information Systems & 58 & Uber & 31 \\
\hline Sustainable Development & 55 & Information Use & 24 \\
\hline Commerce & 50 & Ride-sharing & 24 \\
\hline
\end{tabular}

In addition, Figure 2 presents a density map of the co-occurrence analysis pertaining to said terms, linking those which tend to appear together in accordance with their actual position on the map. The central terms and those represented in warmer tones are those which show a closer relation with the others as a whole. 
Figure 2. Density map of the most used keywords based on co-occurrence analysis

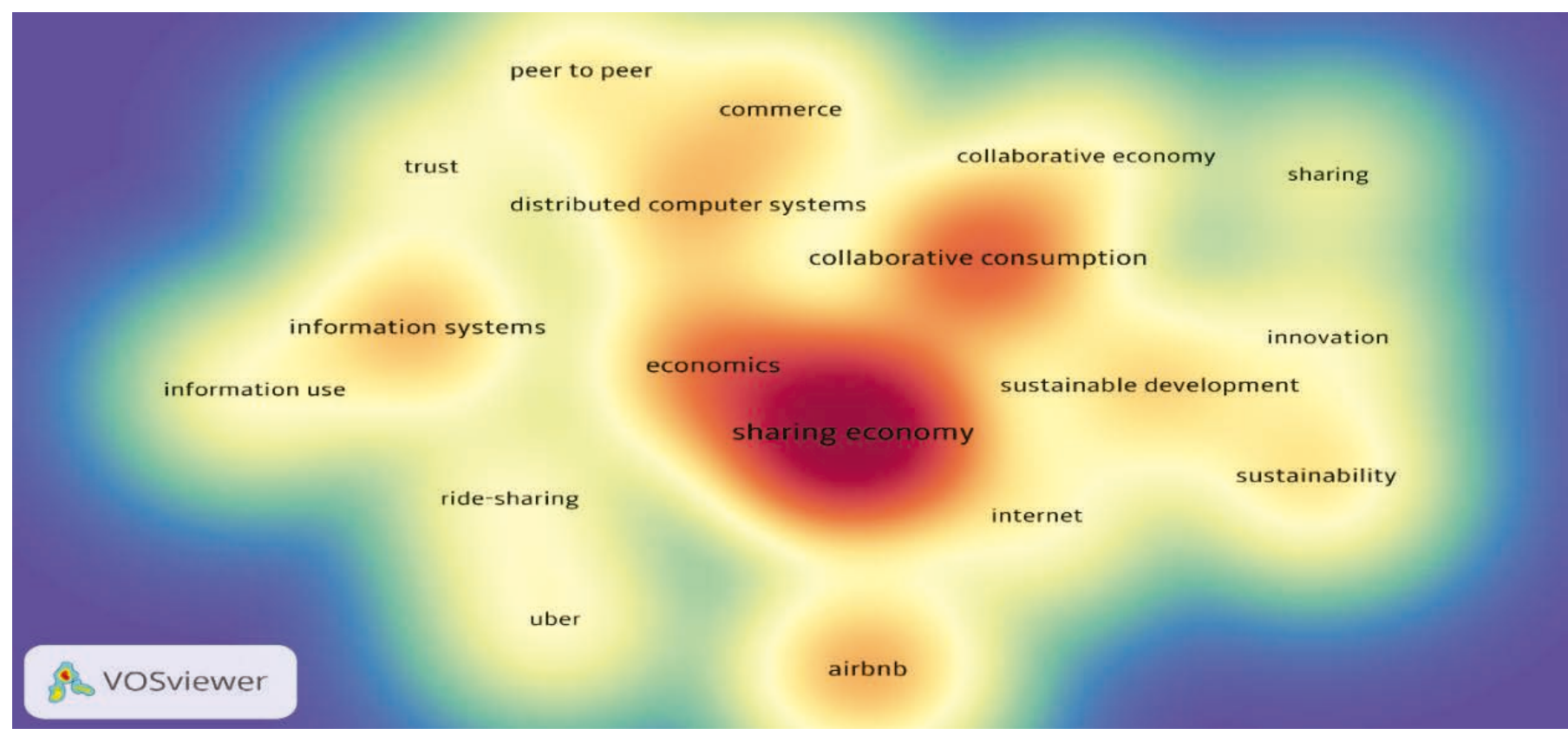

In this map, it is interesting to note the affinity that some terms show among themselves, which helps us to better understand this phenomenon. Terms such as peer-to-peer and information systems (connected by the term trust) help us to comprehend the functioning of most platforms, since they use these information systems to connect peers based on a trusting relationship. Another point that emerges is the affinity between the Uber and Airbnb platforms. Since they are two of the largest exponents of this phenomenon, it is common for case studies to use both of them as a starting point. Finally, we highlight the central aspect of the term economics, next to the term sharing economy. This demonstrates a preoccupation with the economic aspects of sharing platforms.

Another interesting point used to amplify the understanding of these keywords used in the 1018 documents is related to the areas of research in which these studies were conducted. Although the greatest affinity of said studies is with the areas of Business, Management and Accounting (400), Social Sciences (391) or Economics, Econometrics and Finance (154), which are areas that usually share a strong connection, the interest in Computer Sciences (292), Engineering (139) and Environmental Science (130) is conspicuous. Even though some studies are a part of more than one area, which explains the large number of studies in each category, the diversity of topics shows the sharing economy's multidisciplinary character.

\subsubsection{Production per Country}

Among the countries with the greatest number of publications, the United States, the United Kingdom, Germany and China concentrate a larger number of publications in relation to the rest of the countries, as shown in Table 2. However, when conducting the analysis with other indicators, such as citations or h-index, the scenario highlights some other countries, such as Canada $\left(9^{\text {th }}\right)$, the Netherlands $\left(12^{\text {th }}\right)$, Denmark $\left(14^{\text {th }}\right)$ and Finland $\left(15^{\text {th }}\right)$, which gain expressiveness in the citations category with all countries reaching at least the $6^{\text {th }}$ place, tied with countries such as China $\left(4^{\text {th }}\right)$. Said countries, except for the Netherlands, have a C/P indicator higher than 20. Another interesting point to be noted is the fact that the United States only has three representatives while Germany, for instance, has seven. This factor shows that in the United States there is a larger number of researchers working on the subject, but a lower number of publications while in Germany, these authors answer for $45 \%$ of the publications. This indicates that the number of academics directing their efforts towards the subject may still grow if stimulated, as seen in China, which does not have any authors in this ranking and yet has a number of published studies similar to Germany. Other countries that were also left without representation are located in Latin America and Africa, which was already expected given the low productivity shown by these countries. 
Table 2. Countries with the greatest number of publications and their respective indicators

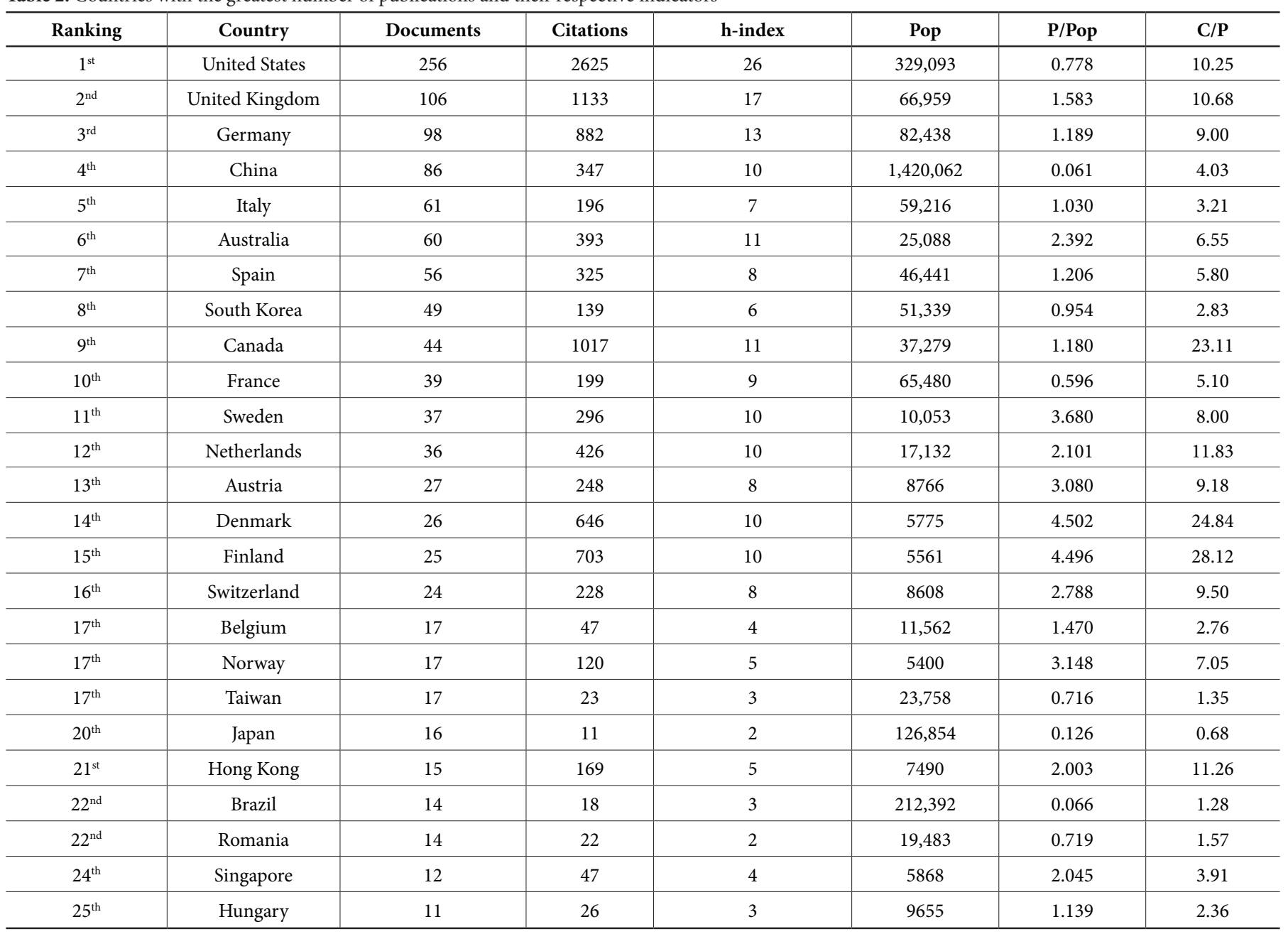

Pop = Population in millions (Worldometers, 2018); P/pop = Publications divided by Population; $\mathrm{C} / \mathrm{P}=$ Citations received divided by the number of publications; h-index only for articles related to sharing economy

While some countries are shown in a positive light, others have substandard performance. South Korea $\left(8^{\text {th }}\right)$, has a number of citations and an h-index comparable to those of Norway $\left(17^{\text {th }}\right)$, which implies that although it has a large number of publications when compared to other countries, their findings are not sufficiently influential. Another country in this situation is Japan $\left(20^{\text {th }}\right)$ which, despite not being highly ranked, is the only country on the list with a number of publications that is higher than its number of citations $(\mathrm{C} / \mathrm{P}<1)$, which means that if the ranking was conducted according to this criterion, Japan would be in a similar position to countries such as Slovenia $\left(47^{\text {th }}\right)$ and the Philippines $\left(48^{\text {th }}\right)$.

Another interesting point is that, preserving the particularities pertaining to different fields, the countries that are producing the knowledge about the sharing economy are the same ones that are at the forefront of many other subjects such as, for instance, innovation (Tello-Gamarra et al., 2018). Of the nations identified by Wong (2019) as the six with the highest number of publications in all areas of knowledge between 1900 and 2017, four of them are in the lea- dership regarding the number of publications about the sharing economy (United States, United Kingdom, Germany and China). This indicates a possible maintenance of these countries at the forefront of knowledge production since this leadership is apparent not only in consolidated subjects but also in emerging subjects such as the one discussed herein.

Finally, we must highlight the large number of recent publications originating in China ( $\left.4^{\text {th }}\right)$. According to Ertz and Leblanc-Proulx (2018), when added to Hong Kong, the country had a total of 49 publications whereas nowadays China individually exhibits a total of 86 published works. This evolution may be explained by the financing the studies have been receiving, with the National Natural Science Foundation of China (NSFC) financing 24 of the studies and appearing as the biggest sponsor among the entities that sponsored the analyzed studies. Among these, 16 were published in 2018. To demonstrate the representativity of this number, the National Science Foundation (NSF), originated in the United States, was the second largest financing entity sponsoring only 13 studies. 


\subsubsection{Authors and publications}

Since this is a recent research area, the production of a study with a higher number of citations ends up highlighting its author, so we ranked the authors by the number of studies they produced. In Table 3 , it is possible to observe which ones have more publications. A minimum of five published studies was necessary for consideration. In this table, some of the commonly listed authors such as Juho Hamari, Chris Martin and Mareike Möhlmann are not listed because they have not published more than four studies. However, the criterion was maintained because the aforementioned authors are later seen in Table 4, which shows the publications with the greatest number of citations.

Table 3. Main authors in number of article publications and their respective indicators

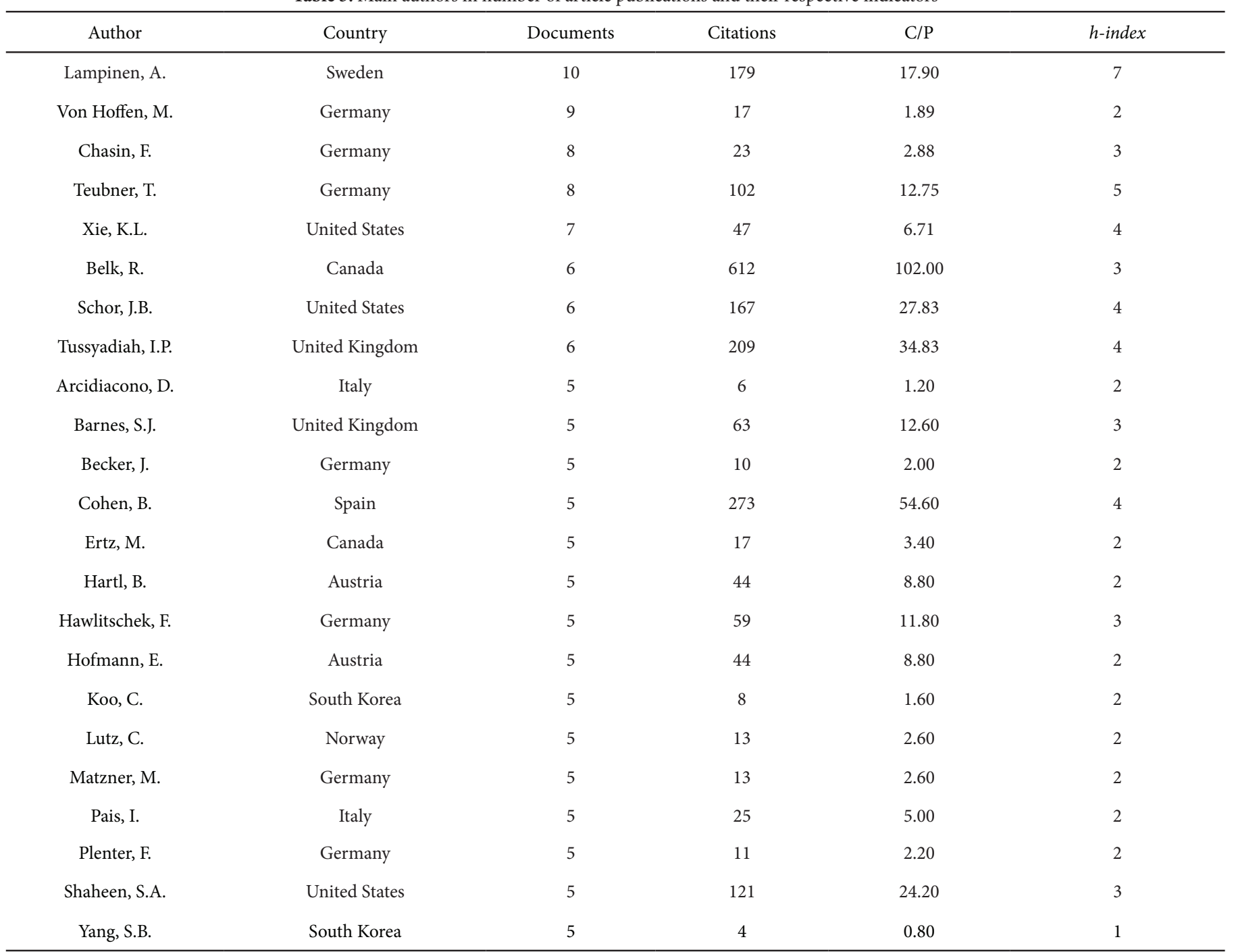

$\mathrm{C} / \mathrm{P}=$ Citations received divided by the number of publications; h-index only for articles related to sharing economy

When analyzing the publications (as show in Table 4), the study by Heinrichs (2013) stands out because it is the only article in the list that is not an original study, but actually a review. Studies by Belk (2014a) and Hamari et al. (2016) stand out when the focus is on the number of citations. Russel Belk is also in evidence because he is the only author with two studies among the most cited (Belk, 2014a; 2014b), which makes him the most cited author on the subject. This success of Belk's articles can be explained by the fact that they are theoretical articles and help to support both sharing and the sharing economy, serving as an epistemological base for the paradigm. 
Table 4. Main publications related to the area

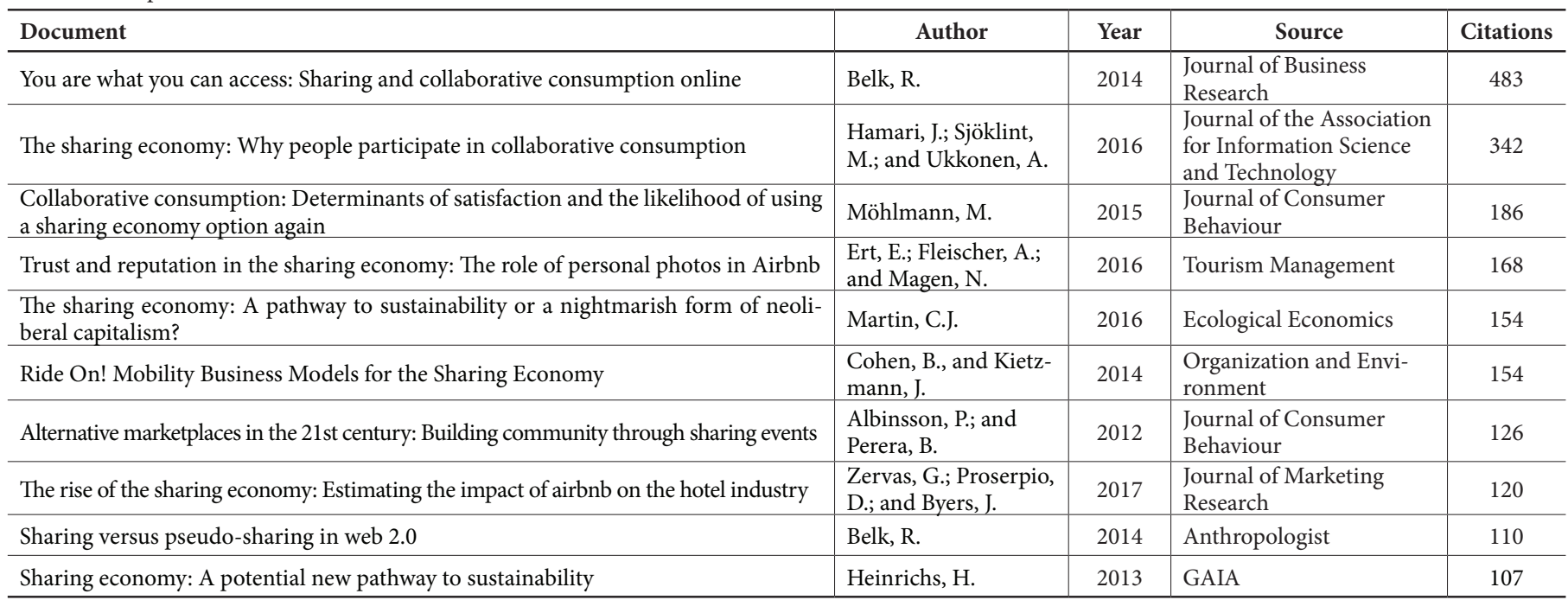

At this point, it is important to analyze the possible reasons behind these articles receiving an elevated number of citations in this research field. One aspect that should be considered is the year of publication. Of the 10 articles in the list, five were published before 2015 (Albinsson and Perera, 2012; Belk, 2014a; 2014b; Cohen and Kietzmann, 2014; Heinrichs, 2013). As with the analyzed corpus, more than $96 \%$ of the production occurred after 2014 . Thus, they conspicuously received more citations as they are the pioneers of their field. However, the year of publication cannot be the only aspect that justifies the inclusion of these articles in this category. Another point that can justify these articles receiving this number of citations has to do with the subject they cover. Upon crossing the subjects of each article with the keywords used in the search, they are all somewhat related to one another. Examples can be found in articles from Belk (2014a; 2014 b), which can be intimately linked to information systems and the internet ( $7^{\text {th }}$ and $12^{\text {th }}$ most used keywords, respectively); Hamari et al. (2016), Möhlmann (2015) and Ert et al. (2016), who cover aspects related to trust and peer to peer relationships $\left(13^{\text {th }}\right.$ and $14^{\text {th }}$ most used keywords, respectively); and Martin (2016) and Heinrichs
(2013), who deal with subjects related to sustainability and sustainable development ( $6^{\text {th }}$ and $8^{\text {th }}$ most used keywords, respectively).

\subsection{Research trends}

Through the formation of the network thanks to the bibliographic coupling technique, is possible to observe the appearance of four well defined clusters, as demonstrated in Figure 3. In this paper, the research trends will be identified from each cluster that was found. These clusters show us which direction research about the sharing economy has been taking, presenting the main interests in the field. Back to the Figure 3, in order to improve visibility, some less significant connection lines were suppressed, as otherwise the map would have been polluted and difficult to understand. In the map, the lines represent the existence of bibliographic coupling between two studies. The thicker the line, the greater the number of studies that share the same references. The size of the circles that represent the studies is directly proportional to the strength of their relation with the other studies as a whole. Each of the four research trends are addressed in the following subsections.

Figure 3. Research trends formation through bibliographic coupling

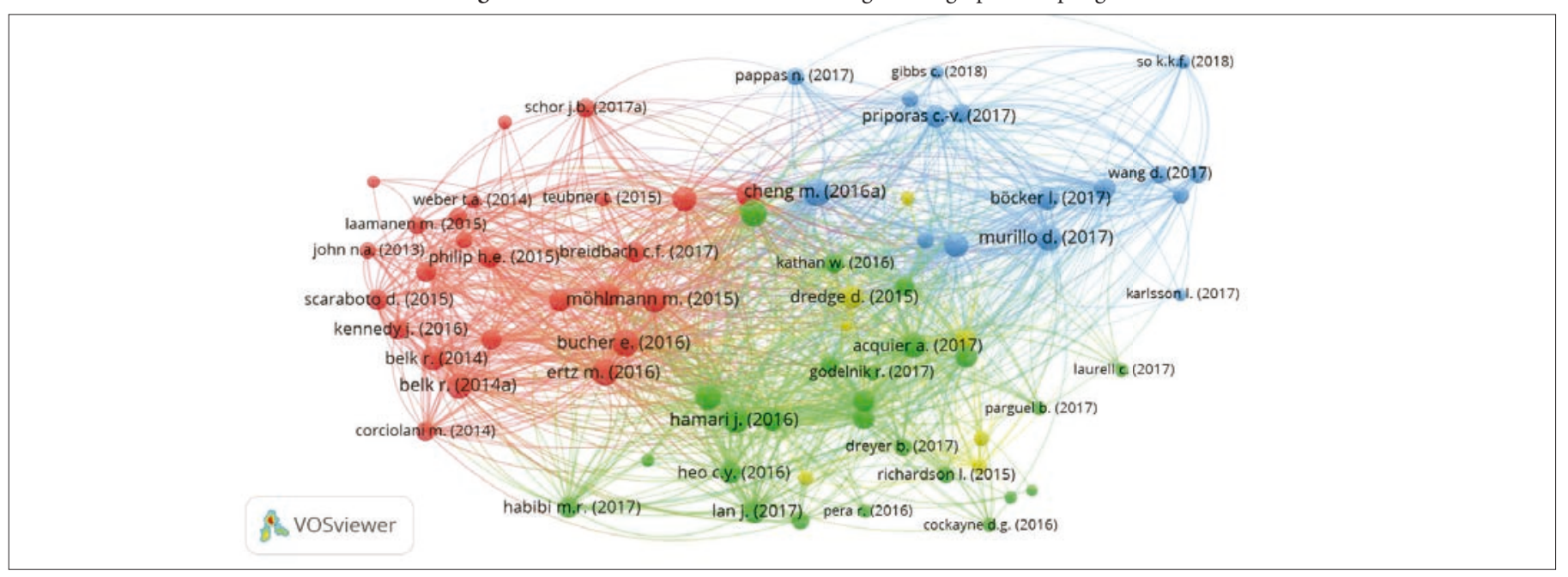

ISSN: 0718-2724. (http://jotmi.org) 


\subsubsection{The act of sharing and its socio-marketing ramifications}

The first research trend can be identified through the first cluster that was found and is represented in red on the map, containing 25 articles that share interconnected references. Among these, four of them are among the most cited articles in the field (Albinsson and Perera, 2012; Belk, 2014a; 2014b; Möhlmann, 2015). In this cluster, two subjects guide most of the production - the act of sharing per se and the consequences of this act's materialization in the market, through alternative types of marketplace or organization and the social impacts that are generated.

Concerning the act of sharing, the concept is analyzed under different perspectives. John (2013) starts with the study of sharing in three different spheres - web 2.0, in the sharing economy itself and in intimate interpersonal relations. The Web 2.0 environment is revisited by Belk (2014b) who analyzes sharing within this sphere and theorizes about the use of the term pseudo-sharing as a reference to sharing with profit-based motivations, lacking the sense of belonging to a community and expectations of reciprocity. Sharing economy, in the guise of collaborative consumption, is also revisited in the analysis of the act of sharing, specifically to which point the various parts of collaborative consumption can truly be considered sharing (Belk, 2014a). This preoccupation in delimiting the borders of collaborative consumption based on the act of sharing is also present in Ertz et al. (2016), who aims to create a scope of the phenomenon and compare it to other forms of exchange. With another approach, Corciolani and Dalli (2014) create an integrating model between the theories of sharing, gift-giving and exchange. Additionally, Scaraboto (2015) attempts to explain the existence of these hybrid models of economy that are formed. Thus, types of marketplaces and sharing-oriented organization appear and are grouped within this cluster as they are based on this central aspect of the sharing economy - sharing. Albinsson and Perera (2012) explore these emerging alternative markets that are organized with a focus on the consumer without the need for monetary exchange. Examples of these forms of organization based on pure sharing are seen from land sharing (McArthur, 2015) to time banks (Laamanen et al., 2015). With this in mind, studies that search for ways of exploring this growth are not exactly a surprise (Matzler et al., 2015). Finally, the fact that these new forms of transactional organization reflect on society is also not a surprise. Schor and Attwood-Charles (2017) worry about the impact that is caused on society and conduct reflections on labor and on inequality. Said inequality is shown to be relevant once again in Schor (2017). These articles, albeit with different objectives, are connected due to the fact that they somehow focus on sharing.

\subsubsection{Toward a sharing economy theory}

The second research trend is identified in green and also contains 25 articles. From these, only Hamari et al. (2016) is among the most cited. The concern in this trend is evident in the number of articles that use the same format. Most of them search for a framework as a way of trying to organize the still dispersed concepts that are related to this phenomenon. The search probably occurs due to the gaps that are still present in this field of study. In other words, these articles have in common the search for a theory of the sharing economy.
If the first cluster analyzes of the act of sharing, this one begins to gather the profit-oriented characteristics of these platforms. Richardson (2015) addresses this matter by emphasizing the ambiguous character of the sharing economy, which is a new type of consumption that establishes new patterns for the same problems that are present in conventional transactions. Thus, the frameworks appear in an attempt to fulfill the conceptual gaps with various foci or analysis units. Acquier et al. (2017) searches for a model that explains some concepts about the sharing economy, basing the analysis on its three "cores" and, from these, creating models that appear from their overlap. Benoit et al. (2017) brings forth the understanding of the phenomenon using the number and types of actors, the nature of the transaction and the guidelines for exchange as the starting point for a framework and as a point of analysis. In a different institutional situation, Dreyer et al. (2017) attempts to unveil the relationship between the economic context (in this case an emerging economy) and the values of the interested parties and their impact on the collaborative consumption business models. Given the diversity of the created frameworks, Muñoz and Cohen (2017) evaluate the business models for 36 different companies (all included in the sharing paradigm) and leverage some dimensions that existed in previous studies in order to identify and, somehow, unify these different frameworks. It is important to point out that the sharing economy not only originates frameworks but also influences preexisting business models (Kathan et al., 2016). To complement the created structures and models, the institutional theoretical models are also applied to reading and to the comprehension of their workings. Watanabe et al. (2017) demonstrates that the success or failure of a sharing platform may stem from institutional sources. Mair and Reischauer (2017) also use organizational institutionalism theories, but focusing on culture and pluralism in the guidance of a research agenda. Laurell and Sandstrom (2017), although they do not necessarily follow this research agenda, are able to construct the concepts and actors that guide the sharing economy in their country (Sweden) from the viewpoint of institutional theory by using Social Media Analysis to collect data. The preoccupation with defining limits and concepts in this field of research (and the absence of a consensus) as well as the need to identify the impact that these models bring about makes theoretical studies recurrent.

In the mapping analysis, it is also possible to identify that this cluster is in a central position among the others, conducting mediation mostly between the cluster that deals with the act of sharing and its socio-marketing ramifications (red cluster) and the one that contains sharing platforms and the use of new technologies (blue cluster, mentioned below). This is an interesting find since there is a polarization of sorts between these research trends. On one hand, the focus is on the act of sharing while, on the other, the platforms are in focus, not the act itself. The connection between both trends happens thanks to this cluster which has to do with theoretical foundations and has the potential to join both aspects. Nonetheless, it is from the union of this cluster and the blue one (sharing platforms and the use of new technologies) that we have the emergence of the cluster that deals with the future directions of this research field (yellow). This can be justified by the fact that some academics may be questioning the orientation of the sharing economy considering the platforms that are emerging and the new technology that is being used, which can divert the research field from its roots. 


\subsubsection{Sharing platforms and the use of new technologies}

A third research trend, which is represented by the blue cluster, contains 16 articles and is possibly the one that will awaken the most practical interest. It is headed in a direction which points to a preoccupation regarding current sharing platforms (mostly exemplified by AirBnb), factors that lead to their use and the technologies utilized alongside these platforms. However, it was the only cluster which did not contain an article among the most cited. In their study, Bocker and Meelen (2017) aim to identify the factors that stimulate different social groups to participate in the sharing economy. Pappas (2017) uses a more focused analysis intending to identify these factors on peerto-peer platforms in the hotel industry. Mao and Lyu (2017) use theories from the psychology field to increase understanding specifically about the AirBnb platform, creating a model in order to explain the relations that lead travelers to opt for using the platform again. Merely as a form of illustrating AirBnb's impact, at least eight other articles in this cluster focus on this platform in their analyses. For example, Gibbs et al. (2018) and Wang and Nicolau (2017) have similar objectives - both studies intend to analyze the prices practiced within this hospitality platform. Karlsson et al. (2017) analyzes a factor which is specific to AirBnb - the possibility to refuse a reservation. AirBnb's high expressiveness is not exactly a surprise. As demonstrated in section 4.1.2, AirBnb is the third most cited keyword, only falling behind the phenomenon's nomenclature. Finally, although less expressively, the use of technologies alongside these platforms is shown to be relevant. Hawlitschek et al. (2018) analyzes the integration of Blockchain functionalities in the context of the sharing economy while Zhu et al. (2017) makes use of technology adoption models in order to investigate what motivates consumers to use an emerging mobile application linked to the sharing economy.

\subsubsection{The future of the sharing economy}

Finally, we arrive at the fourth research trend, which is represented by the yellow cluster. It is the one with the smallest number of articles, numbering only seven. This indicates that although the discussed theme is present in the studies, it is not considered as relevant as the others. With a slightly larger critical load when compared to the other articles, these studies question the direction the field has been taking and reflect critically on recent advances. More than merely advancing towards a theoretical construction for the sharing economy, which explains its overlap with the green cluster, this cluster focuses on the directions the field of study is taking. In other words, what the next steps for the sharing economy will be.

Barnes and Mattsson (2016) aimed to identify, aside from the drivers and inhibitors of this phenomenon, the possible developments in the sharing economy for the next ten years. Despite the fact that Puschmann and Alt (2016) use a framework, which means the study could have some affinity with the second cluster, the study revisits theoretical concepts in order to direct questions for future research. Dredge and Gyimóthy (2015), on the other hand, support greater parsimony in the allegations that are made about the sharing economy in the context of the tourism industry. Hobson and Lynch (2016) also discuss the directions in which circular economy is going, using the sharing economy as an analysis unit. Martin (2016), in general, uses online discourse analysis to try and identify the incoherence and ambiguities that are present in the discourse about the sharing economy.

With the cluster definitions complete, Figure 4 complements Figure 3, using the same graphic representation but associating its colors to the studies' publication years.

Throughout the network shown in accordance with the publication

Figure 4. Network through bibliographic coupling showing years of publications of the works

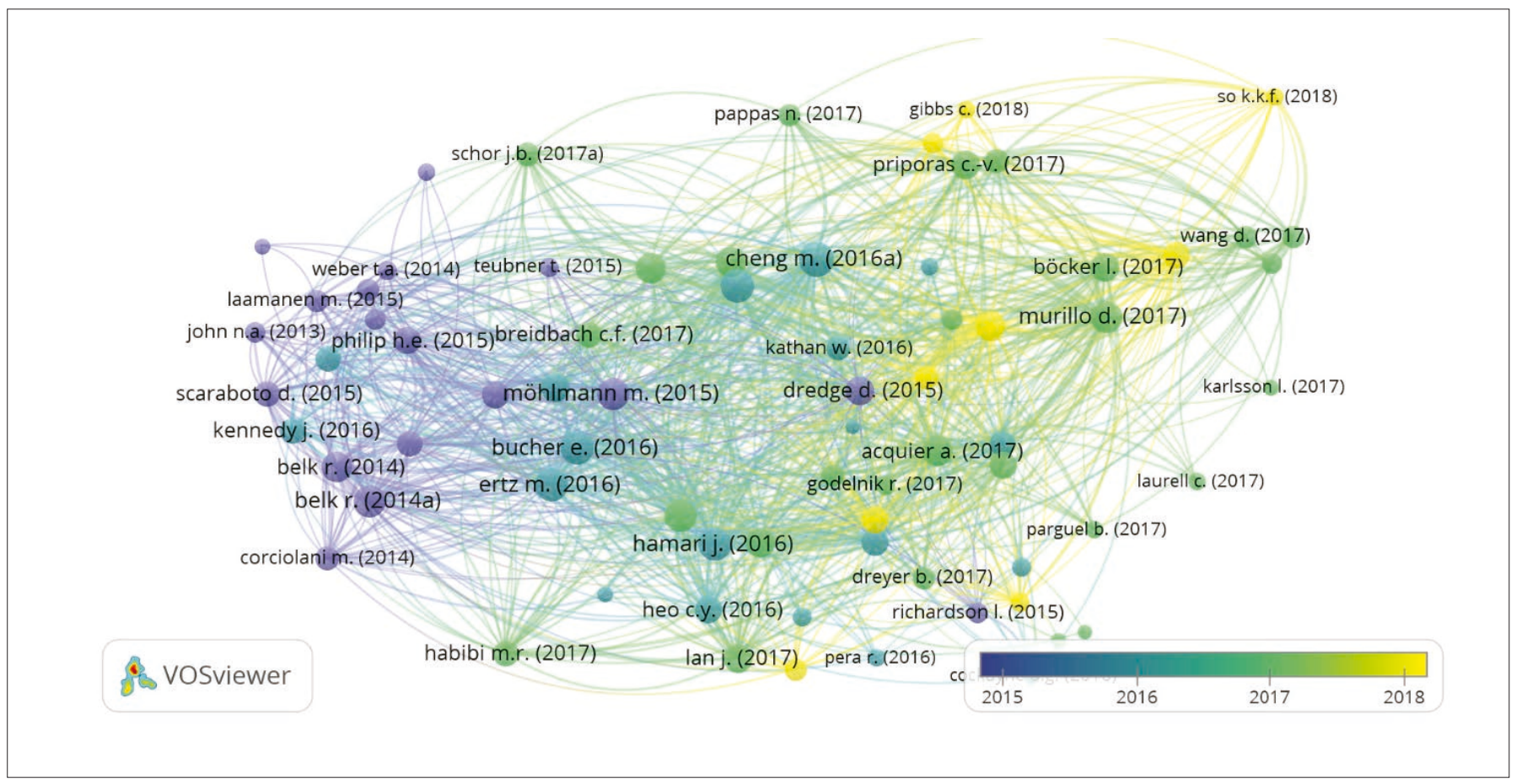

ISSN: 0718-2724. (http://jotmi.org)

Journal of Technology Management \& Innovation (c) Universidad Alberto Hurtado, Facultad de Economía y Negocios. 
periods, it is possible to conduct an analysis by associating the clusters with the years in which their articles were published. While studies that focus on sharing occurred at the beginning of this field's existence, a redirection towards the platforms becomes evident in the maturation process. The separation of the clusters from the epistemological bases was to be expected. Martin (2016) had already sounded the alert for the dissonance between the initial and current motivations behind the research. This recent decline in the interest in the act of sharing and the increase in profit-oriented platforms reinforces the suspicion of an institutional process that requires better understanding. On the other hand, the articles that focus on the sharing economy's theoretical construction are present regardless of the year of publication, something that is expected to remain until more concrete answers are obtained about the field.

With this analysis, we present Figure 5, which summarizes the findings on research trends up to this moment. Something that stands out is the fact that the term evolution does not refer to an evolutionary process per se, but actually to the field's development.

Figure 5. The evolution of research trends about the sharing economy

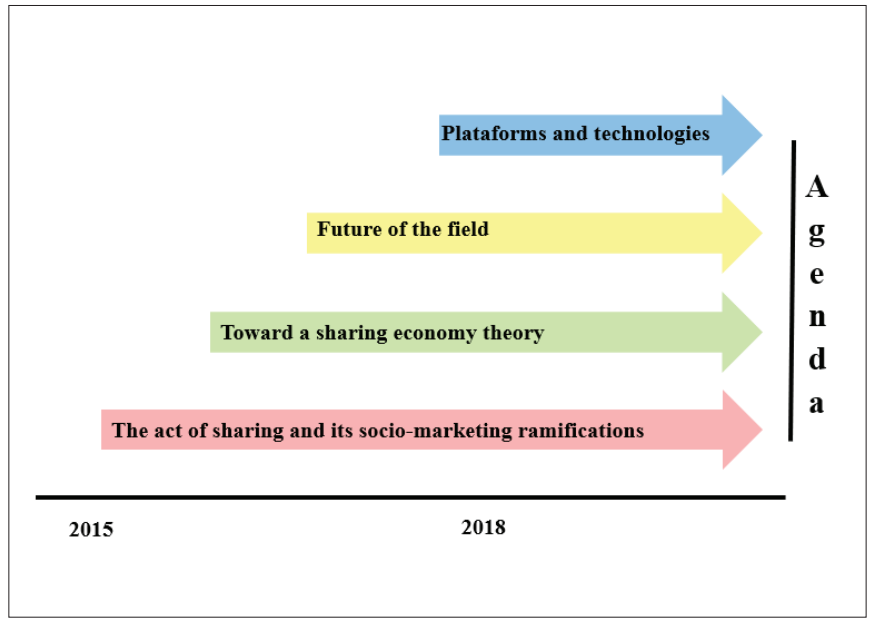

Based on this figure, it is possible to comprehend the formation of this research field, its evolution to what is currently in focus and the directions it may take. In the beginning, the act of sharing and the implications of sharing as a type of economy were the main focus. With time, however, this line of research began to share space with other preoccupations. Studies on the theoretical comprehension of the sharing economy phenomenon began to appear, as well as worries about the future of the research field. More recently, however, the platforms and new technologies have been in vogue. This may have to do with the sharing platforms reaching a position of prominence in the market, leading to the appearance of many similar platforms through a process of mimetic institutional isomorphism.

With the research trends defined and the research field's development within the last few years elucidated, it is now possible to focus on the research agenda, which is responsible for providing possible pathways to follow based on the studies that have already been conducted.

\subsection{Directions for future research}

The different articles that were used in the bibliographic coupling address some research opportunities and needs for development in the field. In order to organize the topics and make it easier for interested researchers to correlate the research trend that generates the most affinity and the given research suggestions, this presentation will be stratified by cluster. The exception pertains to the cluster that refers to the future of the sharing economy because the very suggestions that are given here, regardless of which cluster was considered, aim for the future enrichment of the phenomenon, meaning that a more specific approach for this cluster would be redundant.

Concerning the act of sharing and its socio-marketing implications, studies that focus on the roots of sharing platforms as conceived by Belk (2014b) may lead these topics towards a different direction than they seem to be currently taking (towards a profit-oriented institutionalism). Also, these platforms have specific structural problems and needs. Greater attention given to these necessary structures will also create a solid base for new platforms to prosper or for currently acting platforms to return to the two initial conditions. Why are profitoriented platforms achieving significant success and those that are directed only towards sharing not following this growth? What are the specifics behind the profit-oriented platforms and those that do not aim to make a profit?

As for the theoretical constructions, analyzing the existing pressures on this phenomenon may bring about interesting insights, especially from the institutionalist viewpoint. With the pressures that currently hang over these organizations, are we faced with a process of institutional isomorphism? From another perspective, cross-cultural studies are also interesting, though scarce. The validation of previously structured models in different countries is an important step towards the consolidation of concepts and frameworks, something that is still extremely fragile and vulnerable in current research. Furthermore, the act of conducting different types of research is used in other fields of knowledge and may be included in this one. Experiments and longitudinal studies are mere examples of data collection tools that can be used and that have the potential to bring a new perspective to the analyses, since measurement has been very much based on user intent, and not on user behavior per se. At this point, there are no new research questions to be included, but interested researchers can use different methodologies or environments to which they can be applied in order to gain a different perspective on the phenomenon.

The platforms are of great practical interest, so this is apparently the line of research that is the closest to reaching saturation and it is not uncommon to observe studies with very similar objectives. However, still in this cluster, the use of technology and technological devices is a research gap that can be included in the construction of interdisciplinary knowledge. From a practical viewpoint, issues that test the evaluation systems are interesting. Up to what point is the quality of the service rendered by an individual being measured, and not the quality of what is offered by the platform? Or, from a more interdisciplinary viewpoint, which are the main technological capacities 
present in sharing economy firms? What is the role of communication technologies and information in the adaptability of these platforms in different institutional situations? We believe that the answers to all of the questions addressed in this section may lead to important advancements in the future of the sharing economy.

\section{Conclusions}

The present study aimed to present a quantitative panorama of studies related to the sharing economy, as well as a map of the directions taken by recent research studies through the identification of the main research lines that have been adopted. For this purpose, bibliometric data about the sharing economy was collected and analyzed. We believe that this study provides a panoramic view of the studies related to this subject, with new results being presented through citation analysis. A new perspective was also offered through the bibliographic coupling technique. This allows us to position new researchers in the field's main research trends, which in addition to our research agenda will enable the advancement of knowledge production in the field and can lead to clearer definitions.

Upon using the bibliographic coupling technique, the results from the clusters were different than what was found by Ertz and LeblancProulx (2018). This can be explained by the fact that in the 2018 study, due to the bibliometric tool that was employed, the panorama that was obtained was that of the field's roots while the technique used in this study and the focus rest on the knowledge that is being produced. Furthermore, we have verified in this study that the number of publications will not necessarily be linked to an author's influence in the field (Tahamtan et al., 2016). For instance, Russel Belk is the most cited author with two publications among the ten most referenced and yet he is only the sixth ranking author in number of publications. The opposite also happens; that is, authors with many published articles are not necessarily the most influential in this field of study.

Furthermore, the identification of research trend evolution is possibly the main contribution brought on by this analysis. This identification makes it possible to comprehend the research field and its development. While the first publications focused on sharing as an act and its implications for the market and for society, the topics analyzed in the studies changed with time. In a first moment, we identified an approach that proposed the creation of a theoretical foundation in an attempt to fill in the gaps that exist in the field. Recently, however, the analyses have been based on sharing platforms and the technology they use. This can be explained due to the fact that these platforms enjoy growing protagonism in the market, which turns them into a model for emerging businesses or for those that need to adapt to current times.

As a limitation, some of the studies were excluded from this analysis and the evaluation that led to the exclusion was linked to the inclusion and exclusion criteria established by the authors, which may represent a bias in this study. Also to be considered is that fact that the present study did not consider publications outside of the Scopus database. With this in mind, we suggest that for future bibliometric studies, the analysis should consider the production of books and other references that shy away from traditional bases, as well as measurements at a local level since, due to the coverage in the selected database, there is a possible bias due to not having found publications that happen in journals of less expressiveness and that are not indexed.

\section{References}

Acquier, A. et al. (2017). Promises and paradoxes of the sharing economy: An organizing framework. Technological Forecasting and Social Change, 125, 1-10.

Albinsson, P., \& Perera, B. (2012). Alternative marketplaces in the 21st century: Building community through sharing events. Journal of Consumer Behaviour, 11(4), 303-315.

Barnes, S., \&Mattsson, J. (2016). Understanding current and future issues in collaborative consumption: A four-stage Delphi study. Technological Forecasting and Social Change, 104, 200-211.

Belk, R. (2010). Sharing. Journal of Consumer Research, 36(5), 715-734.

Belk, R. (2014a). You are what you can access: Sharing and collaborative consumption online. Journal of Business Research, 67, 1595-1600.

Belk, R. (2014b). Sharing Versus Pseudo-Sharing in Web 2.0. Anthropologist, 18(1), 7-23.

Benoit, S. et al. (2017). A triadic framework for collaborative consumption (CC): Motives, activities and resources \& capabilities of actors. Journal of Business Research, 79, 219-227.

Bloomberg. (2018, January 19). Uber Valued at $\$ 120$ Billion in an IPO? Maybe. Retrieved from https://www.bloomberg.com/news/articles/2018-10-16/uber-valued-at-120-billion-in-an-ipo-maybe.

Böcker, L., \& Meelen, T. (2017). Sharing for people, planet or profit? Analysing motivations for intended sharing economy participation. Environmental Innovation and Societal Transitions, 23, 28-39.

Bonilla, C. et al. (2015). Economics in Latin America: a bibliometric analysis. Scientometrics, 105(2), 1239-1252.

Botsman, R., \& Rogers, R. (2010a). What's Mine Is Yours: The Rise of Collaborative Consumption. New York, NY: Harper Business.

Botsman, R., \& Rogers, R. (2010b). Beyond Zipcar: Collaborative Consumption. Harvard Business Review, 88(10), 30-30.

Brown, J. (2017). Curating the "Third Place"? Coworking and the mediation of creativity. Geoforum, 82, 112-126.

Cheng, M. (2016). Sharing economy: A review and agenda for future research. International Journal of Hospitality Management, 57, 60-70. Cohen, B., \& Kietzmann, J. (2014). Ride on! Mobility Business Models for the Sharing Economy. Organization \& Environment, 27(3), 279-296. 
Corciolani, M., \& Dalli, D. (2014). Gift-giving, sharing and commodity exchange at Bookcrossing.com: new insights from a qualitative analysis. Management Decision, 52(4), 755-776.

Dredge, D., \& Gyimóthy, S. (2015). The collaborative economy and tourism: Critical perspectives, questionable claims and silenced voices. Tourism Recreation Research, 40(3), 286-302.

Dreyer, B. et al. (2017). Upsides and downsides of the sharing economy: Collaborative consumption business models' stakeholder value impacts and their relationship to context. Technological Forecasting and Social Change, 125, 87-104.

Ellegaard, O. (2018). The application of bibliometric analysis: disciplinary and user aspects. Scientometrics, 116(1), 181-202.

Elsevier. (2019, January 19). Scopus. Retrieved from https://www.elsevier.com/solutions/scopus.

Emarketer. (2017, January 19). US adult sharing economy users and penetration, 2016-2021. Retrieved from https://www.emarketer.com/Chart/US-Adult-Sharing-Economy-Users-Penetration2016-2021-millions-of-adult-internet-users/209547.

Ert, E. et al. (2016). Trust and reputation in the sharing economy: The role of personal fotos in Airbnb. Tourism Management, 55, 62-73.

Ertz, M. et al. (2016). Collaborative Consumption: Conceptual Snapshot at a Buzzword. Journal of Entrepreneurship Education, 19(2), 1-23.

Ertz, M., \& Leblanc-Proulx, S. (2018). Sustainability in the collaborative economy: A bibliometric analysis reveals emerging interest. Journal of Cleaner Production, 196, 1073-1085.

Ertz, M. \& Leblanc-Proulx, S. (2019). Review of a proposed methodology for bibliometric and visualization analyses for organizations: application to the collaboration economy. Journal of Marketing Analytics, 7, 84-93.

Forbes. (2018, January 19). As a rare profitable unicorn, Airb$n b$ appears to be worth at least $\$ 38$ Billion. Retrieved from https:// www.forbes.com/sites/greatspeculations/2018/05/11/as-a-rareprofitable-unicorn-airbnb-appears-to-be-worth-at-least-38-billion/\#672687862741.

Frenken, K., \& Schor, J. (2017). Putting the sharing economy into perspective. Environmental Innovation and Societal Transitions, 23, 3-10.

Gibbs, C. et al. (2018). Pricing in the sharing economy: a hedonic pricing model applied to Airbnb listing. Journal of Travel \& Tourism Marketing, 35(1), 46-56.

Hagiu, A., \& Wright, J. (2018). The status of workers and platforms in the sharing economy. Journal of Economics \& Management Strategy, 28(1), 97-208.
Hamari, J. et al. (2016). The Sharing Economy: Why People Participate in Collaborative Consumption. Journal of the Association for Information Science and Technology, 67(9), 2047-2059.

Harzing, A., \& Alakangas, S. (2016). Google Scholar, Scopus and the Web of Science: a longitudinal and cross-disciplinary comparison. Scientometrics, 106, 787-804.

Heinrichs, H. (2013). Sharing Economy: A Potential New Pathway to Sustainability. Gaia - Ecological Perspectives for Science and Society, 22(4), 228-231.

Hirsch, J. (2005). An index to quantify an individual's scientific research output. Proceedings of the National Academy of Sciences of the United States of America, 102(46), 16569-16572.

Hobson, K., \& Lynch, N. (2016). Diversifying and de-growing the circular economy: Radical social transformation in a resource-scarce world. Futures, 82, 15-25.

John, N. (2013). The social logics of Sharing. The Communication Review, 16(3), 113-131.

Kathan, W. et al. (2016). The sharing economy: Your business model's friend or foe?. Business Horizons, 59(6), 663-672.

Karlsson, L. et al. (2017). May I sleep in your bed? Getting permission to book. Annals of Tourism Research, 62, 1-12.

Kessler, M. (1963). Bibliographic coupling between scientific papers. American Documentation, 14(1), 10-25.

Laamanen, M. et al. (2015). Mobilising collaborative consumption lifestyles: a comparative frame analysis of time banking. International Journal of Consumer Studies, 39(5), 459-467.

Laurell, C., \& Sandström, C. (2017). The sharing economy in social media: Analyzing tensions between market and non-market logics. Technological Forecasting \& Social Change, 125, 58-65.

Mair, J., \& Reischauer, G. (2017). Capturing the dynamics of the sharing economy: Institutional research on the plural forms and practices of sharing economy organizations. Technological Forecasting and Social Change, 125, 11-20.

Mao, Z., \& Lyu, J. (2017). Why travelers use Airbnb again?: An integrative approach to understanding travelers' repurchase intention. International Journal of Contemporary Hospitality Management, 29(9), 2464-2482.

Martin, C. (2016). The sharing economy: A pathway to sustainability or a nightmarish form of neoliberal capitalism?. Ecological Economics, 121, 149-159.

Matzler, K. et al. (2015). Adapting to the Sharing Economy. MIT Sloan Management Review, 56(2). 
McArthur, E. (2015). Many-to-many exchange without money: why people share their resources. Consumption Markets \& Culture, 3, 239-256.

Merigó, J. et al. (2015). A bibliometric overview of the Journal of Business Research between 1973 and 2014. Journal of Business Research, $68,2645-2653$.

Möhlmann, M. (2015). Collaborative consumption: determinants of satisfaction and the likelihood of using a sharing economy option again. Journal of Consumer Behaviour, 14, 193-207.

Mongeon, P., \& Paul-Hus, A. (2015). The journal coverage of Web of Science and Scopus: a comparative analysis. Scientometrics, 106(1), 213-228.

Muñoz, P., \& Cohen, B. (2017). Mapping out the sharing economy: A configurational approach to sharing business modeling. Technological Forecasting \& Social Change, 125, 21-37.

Pappas, N. (2017). The complexity of purchasing intentions in peerto-peer accommodation. International Journal of Contemporary Hospitality Management, 29(9), 2302-2321.

Podsakoff, P. et al. (2008). Scholarly Influence in the Field of Management: A Bibliometric Analysis of the Determinants of University and Author Impact in the Management Literature in the Past Quarter Century. Journal of Management, 34(4), 641-720.

Price, J. (1975). Sharing: The integration of intimate economies. Anthropologica, 17(1), 3-27.

Puschmann, T., \& Alt, R. (2016). Sharing economy. Business \& Information Systems Engineering, 58(1), 93-99.

Ranjbari M., Morales-Alonso G. \& Carrasco-Gallego. R (2019). Conceptualizing the Sharing Economy through Presenting a Comprehensive Framework, Sustainability, 10(7), 2336.

Richardson, L. (2015). Performing the sharing economy. Geoforum, 67, 121-129.

Sainaghi, R. et al. (2020). Sharing economy: a co-citation analysis. $\mathrm{Cu}$ rrent Issues in Tourism, 23(8), 1-9.

Sánchez-Riofrío, A. et al. (2014). Business portfolio restructuring: a comprehensive bibliometric review. Scientometrics, 102(3), 19211950.

Scaraboto, D. (2015). Selling, Sharing, and Everything In Between: The Hybrid Economies of Collaborative Networks. Journal of Consumer Research, 42(1), 152-176.

Schor, J. (2014, September 18). Debating the Sharing Economy. Retrieved from https://www.greattransition.org.
Schor, J. (2017). Does the sharing economy increase inequality within the eighty percent?: findings from a qualitative study of platform providers. Cambridge Journal of Regions, Economy and Society, 10(2), 263-279.

Schor, J., \& Attwood-Charles, W. (2017). The "sharing" economy: labor, inequality, and social connection on for-profit platforms. Sociology Compass, 11(8).

Tahamtan, I. et al. (2016). Factors affecting number of citations: a comprehensive review of the literature. Scientometrics, 107(3), 1195-1225.

Tello-Gamarra, J. et al. (2018). Innovation studies in Latin America: a bibliometric analysis. Journal of Technology Management \& Innovation, 13(4), 24-36.

Van Eck, N., \& Waltman, L. (2007). VOS: A New Method for Visualizing Similarities Between Objects. In Decker R. \& Lenz H., Advances in Data Analysis. Studies in Classification, Data Analysis, and Knowledge Organization. Berlin: Springer.

Van Eck, N., \& Waltman, L. (2010). Software survey: VOSviewer, a computer program for bibliometric mapping. Scientometrics, 84(2), 523-538.

Vogel, R., \& Güttel, W. (2012). The dynamic capability view in strategic management: A bibliometric review. International Journal of $\mathrm{Ma}$ nagement Reviews, 15(4), 426-446.

Wang, D., \& Nicolau, J. (2017). Price determinants of sharing economy based accommodation rental: A study of listings from 33 cities on Airbnb.com. International Journal of Hospitality Management, 62, 120-131.

Watanabe, C. et al. (2017). Consolidated challenge to social demand for resilient platforms - Lessons from Uber's global expansion. Technology in Society, 48, 33-53.

Wong, C. (2019). A century of scientific publication: towards a theorization of growth behavior and research-orientation. Scientometrics, 119(1), 357-377.

Worldometers. (2018, February 19). Countries in the world by population (2018). Retrieved from http://www.worldometers.info.

Zervas, G. et al. (2017). The Rise of the Sharing Economy: Estimating the Impact of Airbnb on the Hotel Industry. Journal of Marketing Research, 54(5), 678-705.

Zhu, G. et al. (2017). Inside the sharing economy. International Journal of Contemporary Hospitality Management, 29(9), 2218-2239.

Zupic, I., \& Cater, T. (2014). Bibliometric methods in management and organization. Organizational Research Methods, 18(3), 429-472. 
